Research, Society and Development, v. 9, n. 11, e98691110511, 2020

(CC BY 4.0) | ISSN 2525-3409 | DOI: http://dx.doi.org/10.33448/rsd-v9i11.10511

\title{
EscapeLab: um jogo de fuga para o ensino de Química
}

EscapeLab: an escape room for teaching Chemistry

EscapeLab: un juego de escape para enseñar Química

Recebido: 30/11/2020 | Revisado: 06/12/2020 | Aceito: 07/12/2020 | Publicado: 10/12/2020

\section{Diogo Xavier de Noronha}

ORCID: https://orcid.org/0000-0001-5018-2007

Instituto Federal de Educação, Ciência e Tecnologia de Minas Gerais, Brasil

E-mail: dexisene@gmail.com

Gabriel da Silva

ORCID: https://orcid.org/0000-0001-9784-5517 Instituto Federal de Educação, Ciência e Tecnologia de Minas Gerais, Brasil E-mail: gabriel.silva@ifmg.edu.br

Vássia Carvalho Soares

ORCID: https://orcid.org/0000-0002-6910-7856

Instituto Federal de Educação, Ciência e Tecnologia de Minas Gerais, Brasil

E-mail: vassia.soares@ifmg.edu.br

\section{Resumo}

O uso de ferramentas didático-pedagógicas alternativas ao quadro e giz, dentre elas os objetos virtuais de aprendizagem, contribuem para uma estratégia de ensino facilitadora do processo de ensino e aprendizagem em química. A gamificação tem se mostrado uma importante estratégia para fortalecer o engajamento dos alunos. Neste contexto, o objetivo deste trabalho foi o desenvolvimento e aplicação de um jogo de fuga, denominado EscapeLab onde a personagem se movimenta pelos ambientes do jogo solucionando enigmas relacionados à conteúdos de química, com a finalidade de estimular a aprendizagem do usuário. O jogo foi aplicado em uma turma do Ensino Médio. Foram aplicados, além de uma pesquisa qualitativa, um pré-teste e um pós-teste para análise do conteúdo assimilado pelos alunos após o uso desta ferramenta didático-pedagógica. Foi observado que o EscapeLab foi bem aceito pelos estudantes e auxiliou na assimilação de conceitos químicos. Trabalhos desta natureza contribuem significativamente para a sociedade uma vez que possibilitam a inclusão digital e têm como base o despertar do interesse pela ciência, através da unificação de estudo e da diversão, utilizando dos jogos virtuais que são hoje tão presentes no cotidiano destes jovens. 
Com base nas ideias pedagógicas construtivistas construídas a partir das ideias de Jean Piaget, pode-se concluir que um jogo educativo, devidamente selecionado e monitorado por um professor apto, é uma excelente ferramenta pedagógica.

Palavras-chave: Escape room; Objeto virtual de aprendizagem; Lúdico; Ferramenta didáticopedagógica; Ensino.

\begin{abstract}
The use of didactic-pedagogical tools alternative to the blackboard and chalk, including virtual learning objects, contribute to a teaching strategy that facilitates the teaching and learning process in chemistry. Gamification has proved to be an important strategy to strengthen student engagement. In this context, the objective of this work was the development and application of an escape game, called EscapeLab where the character moves through the game environments solving puzzles related to chemistry content, in order to stimulate the user's learning. The game was applied to a high school class. In addition to a qualitative research, a pre-test and a post-test were applied to analyze the content assimilated by students after using this didactic-pedagogical tool. It was observed that EscapeLab was well accepted by students and helped to assimilate chemical concepts. Works of this nature contribute significantly to society as they enable digital inclusion and are based on the awakening of interest in science, through the unification of study and fun, using the virtual games that are so present in the daily lives of these young people. Based on constructivist pedagogical ideas built on the ideas of Jean Piaget, it can be concluded that an educational game, properly selected and monitored by an apt teacher, is an excellent pedagogical tool.
\end{abstract}

Keywords: Escape room; Virtual learning object; Playful; Didactic-pedagogical tool; Teaching.

\title{
Resumen
}

El uso de herramientas didáctico-pedagógicas alternativas al pizarrón y la tiza, entre ellos objetos virtuales de aprendizaje, contribuyen a una estrategia de enseñanza que facilita el proceso de enseñanza y aprendizaje en química. La gamificación ha demostrado ser una estrategia importante para fortalecer la participación de los estudiantes. En este contexto, el objetivo de este trabajo fue el desarrollo y aplicación de un juego de escape, denominado EscapeLab, donde el personaje se mueve por los entornos del juego resolviendo acertijos relacionados con el contenido de química, con el fin de estimular el aprendizaje del usuario. El juego se aplicó a una clase de secundaria. Además de una investigación cualitativa, se 
aplicó un pre-test y un post-test para analizar los contenidos asimilados por los estudiantes luego de utilizar esta herramienta didáctico-pedagógica. Se observó que EscapeLab fue bien aceptado por los estudiantes y ayudó a asimilar conceptos químicos. Obras de esta naturaleza aportan de forma significativa a la sociedad ya que posibilitan la inclusión digital y se basan en el despertar del interés por la ciencia, mediante la unificación del estudio y la diversión, utilizando los juegos virtuales tan presentes en la vida cotidiana de estos jóvenes. Con base en ideas pedagógicas constructivistas construidas sobre las ideas de Jean Piaget, se puede concluir que un juego educativo, adecuadamente seleccionado y monitoreado por un docente competente, es una excelente herramienta pedagógica.

Palabras clave: Escape room; Objeto virtual de aprendizaje; Lúdico; Herramienta didácticopedagógica; Ensenãnza.

\section{Introdução}

O ensino de Química, assim como das demais ciências exatas, representa um obstáculo para muitos alunos devido às dificuldades de compreensão e absorção do conteúdo. Defendese que o conhecimento da Química deve permitir a compreensão das transformações químicas no mundo físico (Nunes \& Adorni, 2010).

Estudos feitos na década de 90 já destacavam a dificuldade nas disciplinas iniciais dos cursos nas áreas de Ciências Exatas e este é um fator considerável entre as causas de evasão no ensino superior que se estende até os dias de hoje. Isso se dá principalmente pelo ensino deficitário das disciplinas de exatas nos níveis que antecedem o superior. Outro fator que deve ser mencionado é a forma tradicional com que essas disciplinas, matemática, física e química, são ministradas, deixando uma lacuna na aprendizagem dos alunos (Gregório et al., 2017).

Inovações ou adaptações pedagógicas são sempre bem-vindas ao contexto do ensino da Química, sobretudo se elas forem capazes de fomentar habilidades do século XXI na formação química dos estudantes, tais como a contribuição com a alfabetização digital, o pensamento inventivo e crítico, a utilização de uma ampla variedade de habilidades durante a resolução de problemas, aspectos colaborativos, entre outros benefícios (Cleophas \& Cavalcanti, 2020).

Ryan e Deci (2017) afirmam que a chamada Teoria da Autodeterminação tem se mostrado, atualmente, como teoria motivacional academicamente mais robusta. Esta teoria considera que existem três necessidades intrínsecas aos indivíduos que são inatas, universais e diretamente associadas ao bem-estar mental e físico: a competência, a autonomia e o 
relacionamento.

Neste sentido, a Gamificação se apresenta como uma importante técnica que propõe a aplicação de elementos presentes em jogos como a mecânica, a estética e a dinâmica, a fim de engajar as pessoas, motivar ações, promover o aprendizado e solucionar problemas fora do seu contexto usual de entretenimento (Kapp, 2012). No contexto educacional, sua utilização tem contribuído para aumentar a motivação e o engajamento dos alunos (Gonçalves et al., 2016).

Nos últimos anos, os benefícios proporcionados pelas Tecnologias da Informação e Comunicação (TICs) na educação tem ganhado cada vez mais espaço no processo de ensino e aprendizagem e são uma realidade que atinge todos os níveis de ensino, desde o fundamental até a pós-graduação. Neste contexto, destaca-se o uso dos Objetos de Aprendizagem (OAs).

De acordo Spinelli (2007) um objeto virtual de aprendizagem é um recurso digital reutilizável que auxilia na aprendizagem de algum conceito e, ao mesmo tempo, estimula o desenvolvimento de capacidades pessoais, como, por exemplo, imaginação e criatividade.

Os aspectos pedagógicos mais importantes, quando se diz respeito a facilitar o trabalho de alunos e professores no processo de aquisição de conhecimento por meio de objetos virtuais de aprendizagem, são: a interatividade do estudante com o objeto de aprendizagem; a autonomia do aprendizado, tornando o processo de aprender independente de professores; a cooperação, no sentido de permitir aos aprendizes que façam trocas de informação durante o processo de aprendizagem; a cognição, ressaltando a capacidade do objeto de transmitir um conhecimento real e significativo ao aprendiz; a afetividade que fica responsável pela motivação do aprendiz em estar ultrapassando novos limites e engrandecendo o seu nível de conhecimento (Galafassi et al., 2013).

Além destes aspectos devem ser consideradas características técnicas de um objeto de aprendizagem, tais como: métodos de acesso; capacidade de agrupamento com outros conteúdos; autonomia do objeto de aprendizagem; classificação a fim de facilitar catalogação; durabilidade; interusabilidade ou compatibilidade com múltiplas plataformas; reusabilidade (Galafassi et al., 2013).

Resende et al. (2020) afirmam que o uso de atividades lúdicas pode tornar o processo de aprendizagem mais dinâmico, permitindo ao estudante uma participação ativa na construção do conhecimento, estimulando a criatividade e o desenvolvimento de habilidades, que por sua vez contribuem para sua motivação e autoestima, favorecendo o desenvolvimento cognitivo, psicológico, social e formativo, atendendo assim às novas tendências da educação.

Focetola et al. (2012) afirmam que os jogos educacionais são ferramentas eficientes 
nos processos de ensino e aprendizagem e que complementam as demais atividades pedagógicas. Contudo, Soares (2016) salienta a importância do equilíbrio entre a função lúdica e função educativa dos jogos utilizados na educação.

Há uma diversidade de tipos de jogos que podem ser usados com a finalidade de entreter e ensinar em sala de aula, existindo, ainda, possibilidades de inovação dentro desse segmento, já que se trata de um tema que agrega uma contribuição idiossincrática aos processos de ensino e aprendizagem, bastando, para tanto, alinhar os objetivos traçados para atingir a aprendizagem dos alunos com o currículo (Cleophas \& Cavalcanti, 2020). Para este trabalho foi selecionada a modalidade jogos de fuga, também denominados escape room ou exit games.

Nos jogos de fuga o usuário necessita encontrar pistas, resolver quebra-cabeças e enigmas com objetivo de escapar de uma sala ou ambiente. Neste tipo de jogo o aluno é capaz de desenvolver e utilizar suas habilidades em lógica e resolução de problemas. A versatilidade dos jogos de fuga como objeto virtual de aprendizagem é consequência das inúmeras possibilidades e variedades de quebra-cabeças que podem ser inseridos no contexto do jogo, englobando as diversas áreas do conhecimento, os quais podem ser elaborados para atingir metas específicas dentro do conteúdo abordado.

Sabendo-se que o tema de estudo para este trabalho é a química do ensino médio e reconhecendo-se as vantagens do uso de objetos de aprendizado no ensino, o objetivo deste trabalho foi a elaboração, desenvolvimento e aplicação de um objeto virtual de aprendizagem na forma de um jogo de fuga educativo de química, denominado EscapeLab, buscando obter um ganho na absorção de conhecimento dos alunos, não só pelo enriquecimento visual, mas principalmente por despertar um maior interesse pelo conteúdo quando se faz uso do lúdico, de forma a facilitar a aprendizagem de conteúdos específicos da Química do Ensino Médio.

O desenvolvimento do jogo EscapeLab foi realizado por um aluno do curso de Engenharia de Computação do IFMG Campus Bambuí. Pode-se dizer, portanto, que a construção deste objeto virtual possui mão dupla no processo de aprendizagem, uma vez que foi confeccionado por um aluno de graduação por meio da aplicação dos conhecimentos computacionais adquiridos durante o curso e tem por objetivo auxiliar alunos do Ensino Médio no aprendizado em química. 


\section{Metodologia}

Nesta seção são apresentadas as ferramentas, técnicas e o método de desenvolvimento e teste do jogo desenvolvido, tanto do ponto de vista computacional quanto do pedagógico, com ênfase no conteúdo da química a ser trabalhado.

\subsection{Desenvolvimento do jogo EscapeLab}

O objeto virtual de aprendizagem em seu estado de desenvolvimento requer uma modelagem como parte fundamental do projeto, cuja finalidade é facilitar a compreensão, a programação e a produção do jogo de um modo geral. Após definidos os conteúdos abordados, o estilo do jogo e a jogabilidade, a modelagem de cada elemento a ser utilizado e a criação do diagrama de classes, a implementação do código foi o próximo passo para o objeto virtual de aprendizagem.

Usando a linguagem C\# e a biblioteca UnityEngine a programação foi bastante facilitada. Cada bloco de código, chamado de script é uma extensão da classe MonoBehavior que conta com dois métodos principais chamados Start e Update. O método Start é executado assim que o objeto é instanciado em uma cena. Neste momento, atributos são declarados e inicializados, de modo que o objeto tenha suas características iniciais estabelecidas no momento de sua instanciação. O método Update é executado a cada frame da execução e tem como finalidade atualizar os atributos do objeto em função do tempo decorrido e em função de eventos que possam executar alterações sobre ele. O script deve estar sempre anexado a um objeto de jogo que se encontra em cena ou em um objeto que será instanciado, o que significa ser inserido em cena. Quando a cena é executada, todos os objetos de jogo têm seus scripts executados.

A construção do jogo constitui-se de montar as cenas de jogo, colocar os objetos em cada cena em posições adequadas formando assim um cenário e atribuir a estes objetos funções através dos scripts. Após compiladas várias cenas a primeira é instanciada e através dos scripts contidos nela, as seguintes também podem ser instanciadas de acordo com as ações do jogador. Toda a sequência de cenas tem por objetivo promover o aprendizado de química para o usuário.

A personagem chamada Samara, em homenagem ao elemento Samário de número atômico 62, representa uma cientista e foi modelada utilizando MakeHuman, um software cuja função é a modelagem de personagens em 3D. Após esta modelagem foi usado o Blender 
(CC BY 4.0) | ISSN 2525-3409 | DOI: http://dx.doi.org/10.33448/rsd-v9i11.10511

para criar animações à personagem, as quais são executadas durante o jogo, quando a personagem se move.

Dentro das cenas foram inseridos os quebra-cabeças e situações-problema envolvendo conteúdos de química do primeiro e segundo anos do Ensino Médio. Os conteúdos abordados em cada quebra-cabeça e situação-problema estão elencados na Tabela 1.

Tabela 1 - Conteúdo químico exigido para a resolução de enigmas

\begin{tabular}{ll}
\hline Enigma & Conteúdo químico abordado \\
\hline Quebra-cabeça dos cartões & Dissociação iônica e ionização de substâncias \\
Quebra-cabeça Funções Inorgânicas & Funções inorgânicas \\
Quebra-cabeça Ácido-Base & Indicador ácido-base \\
Sequência de cores para abrir cadeado & Estrutura atômica, transição eletrônica \\
Ligar o computador & Condutividade de soluções iônicas \\
Romper uma corrente & Reação entre ácido e metal, corrosão \\
Produzir fogo & Termoquímica, reações exotérmicas, \\
& características do gás hidrogênio \\
\hline Obter uma senha no espelho & Transição de fases, ebulição, condensação \\
\hline
\end{tabular}

Fonte: Autores (2020).

\subsection{Aplicação do jogo EscapeLab}

Alunos do segundo ano do curso Técnico de Informática do IFMG campus Bambuí foram selecionados para a aplicação e validação do software. Foi disponibilizado no Laboratório de Informática do campus um computador por aluno, de forma que o jogo foi explorado individualmente. Entretanto, foi permitida a comunicação entre os alunos possibilitando a troca de ideias e solução de problemas de forma conjunta, garantindo o aspecto pedagógico da cooperação citado por Galafassi et al. (2013).

Para validação foi realizada uma análise quantitativa por meio de um pré-teste e um pós-teste ambos constituídos pelas mesmas questões. O pré-teste foi aplicado antes do contato 
(CC BY 4.0) | ISSN 2525-3409 | DOI: http://dx.doi.org/10.33448/rsd-v9i11.10511

dos alunos com o jogo, e o pós-teste foi realizado após. Desta maneira foi possível estimar o ganho de conhecimento obtido pelos alunos por meio da comparação dos resultados do préteste e pós-teste. Foram aplicadas 8 questões, sendo 6 questões de múltipla escolha e 2 questões para relacionar colunas. O conteúdo de cada questão está apresentado na Tabela 2.

Tabela 2 - Conteúdo químico contemplado nas questões do pré-teste e pós-teste.

\begin{tabular}{ll}
\hline Questão/tipo & Conteúdo químico abordado \\
\hline 1 (múltipla escolha) & Condutividade de soluções iônicas \\
\hline 2 (múltipla escolha) & Indicador ácido-base, compostos inorgânicos \\
\hline 3 (múltipla escolha) & Reação entre ácido e metal, características do gás hidrogênio \\
4 (múltipla escolha) & Reação entre ácido e metal, corrosão \\
5 (múltipla escolha) & Indicador ácido-base \\
\hline 6 (múltipla escolha) & Termoquímica, reações exotérmicas \\
7 (relacionar colunas) & Funções inorgânicas, classificação de compostos inorgânicos \\
\hline 8 (relacionar colunas) & Dissociação iônica e ionização de substâncias \\
\hline
\end{tabular}

Fonte: Autores (2020).

Como pode ser observado na Tabela 2, grande parte do conteúdo químico necessário para a resolução dos enigmas que compõem o jogo (Tabela 1) foi abordado na análise quantitativa. Além disso, os alunos foram convidados a fazer uma avaliação qualitativa do software, por meio de um questionário que continha 5 questões, onde pode ser avaliada a aceitação do objeto virtual de aprendizagem proposto.

\section{Resultados e Discussão}

A seguir são apresentados e discutidos os resultados do trabalho em 2 dimensões: o jogo computacional desenvolvido e a sua utilização pelos alunos. 


\subsection{Descrição do jogo EscapeLab}

O software desenvolvido é composto por vinte e duas classes além das nativas do Unity $3 D$ e trata-se de um jogo virtual de escape com foco no aprendizado de química. Foi divido em módulos onde o módulo principal, chamado de jogo principal, conta com a classe GameControler, responsável pelo controle geral das preferências do jogador bem como registro do avanço após cada sucesso obtido. Uma imagem da página inicial do jogo EscapeLab é apresentada na Figura 1.

Figura 1 - página inicial do jogo EscapeLab.

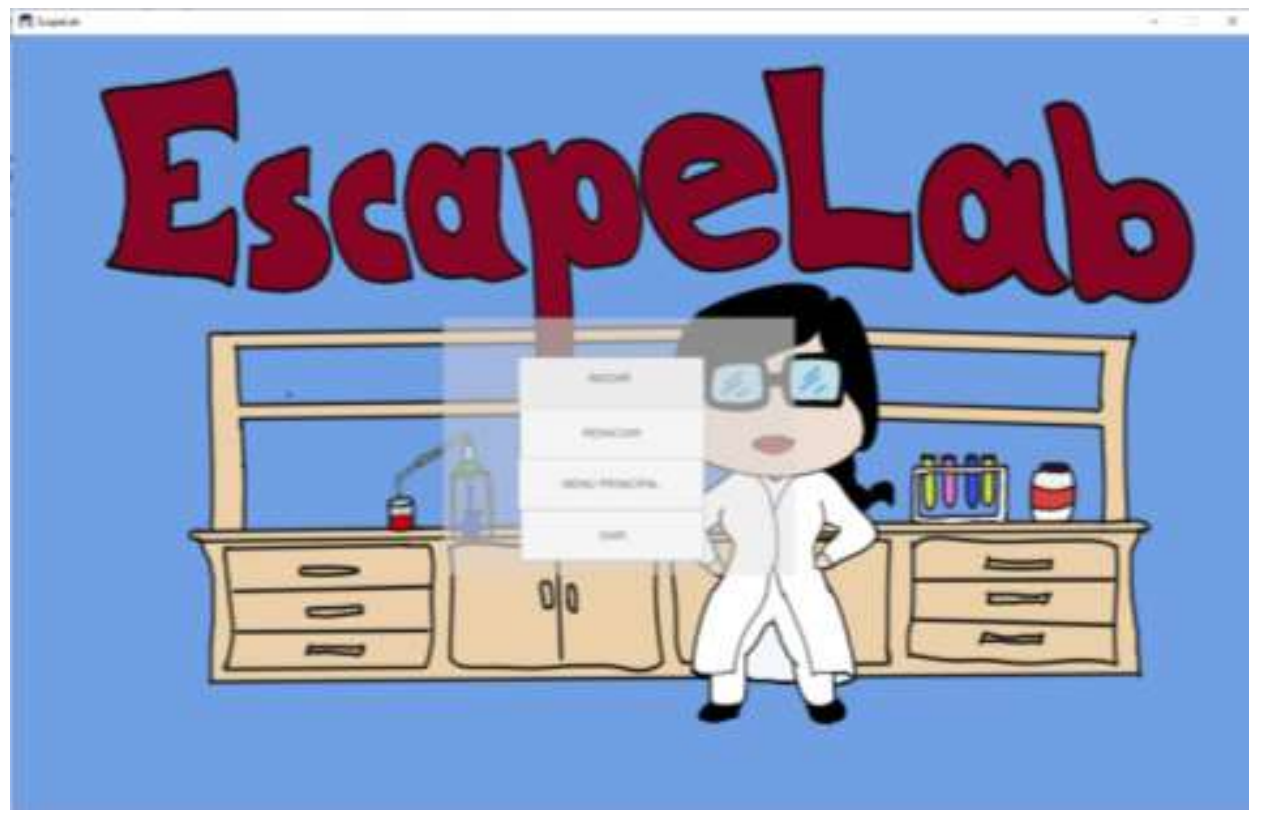

Fonte: Autores (2020).

O jogo permite salvamento automático após a personagem ultrapassar cada porta do cenário de forma que o usuário possa dar continuidade na sua instância de jogo, sem perder suas conquistas prévias, mesmo após o fechamento do aplicativo. Opcionalmente, as conquistas prévias podem ser apagadas ao clicar o botão reiniciar, de modo que o usuário deverá recomeçar o jogo desde a primeira tela.

Além da classe GameController o jogo principal contém várias outras classes responsáveis pela coleta de objetos, uso de objetos, exibição de textos, início e menu de jogo, fim de jogo, volta de cada cena, movimentação da personagem, controle do caderno de anotações e controle dos botões do cofre. Além do módulo principal, outros módulos que 
(CC BY 4.0) | ISSN 2525-3409 | DOI: http://dx.doi.org/10.33448/rsd-v9i11.10511

representam jogos secundários são compostos por várias outras classes que permitem jogabilidades exclusivas para cada módulo.

O jogo apresenta seis cenas e cada uma delas representa um ambiente do prédio do laboratório. O primeiro ambiente é o corredor, onde se encontra a porta de saída trancada (Figura 2). O objetivo final do jogo é revelado assim que o mesmo é iniciado: o jogador necessita encontrar cartões que preenchem as lacunas da tabela periódica localizada na porta de saída.

Figura 2 - Primeiro ambiente e exemplo de texto de contextualização.

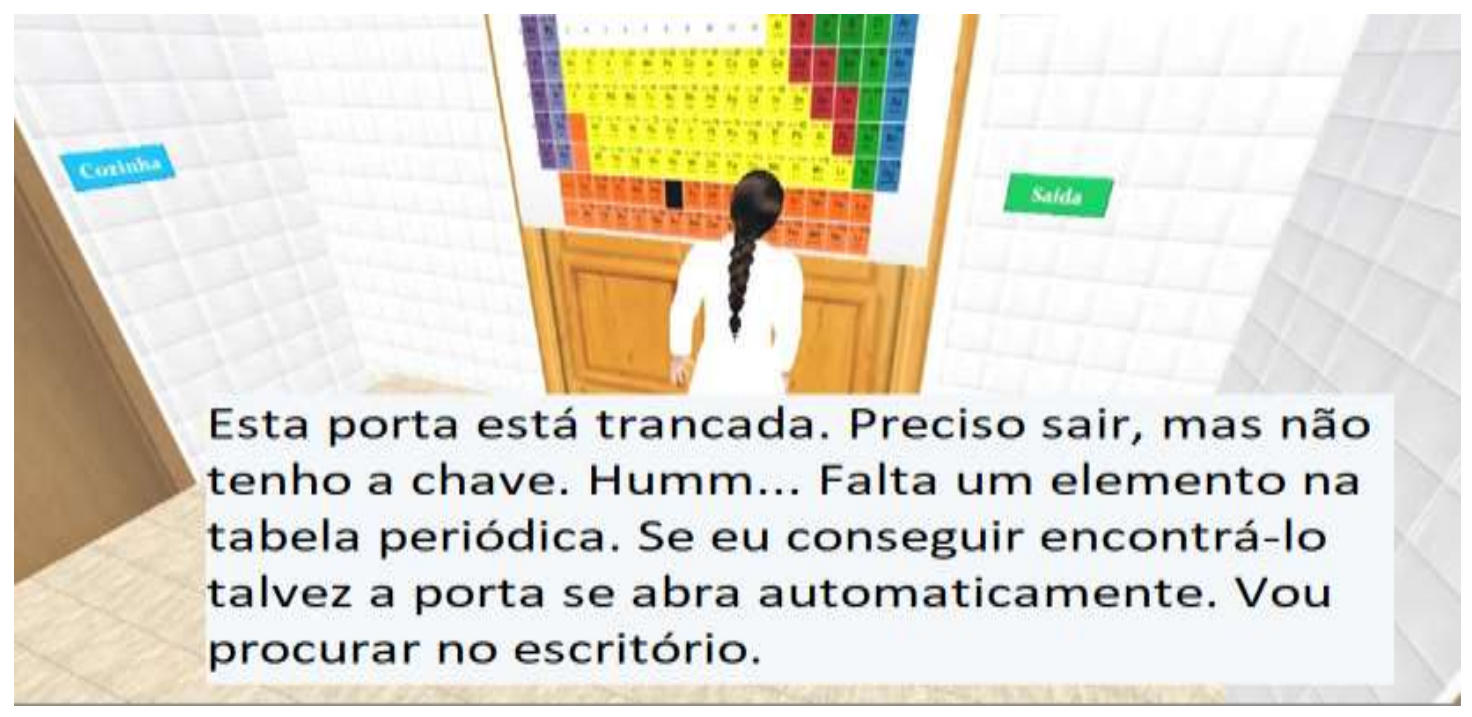

Fonte: Autores (2020).

Como exemplificado na Figura 2, tanto as portas quanto os objetos presentes no jogo trazem textos que permitem melhor contextualização das ações do personagem e fornecem instruções ao usuário de como prosseguir. Este ambiente, além da porta de saída, possui cinco outras portas que permitem acessar as outras cenas.

Os demais ambientes de jogo (Figura 3) são o laboratório, o banheiro, o almoxarifado e a cozinha. 
(CC BY 4.0) | ISSN 2525-3409 | DOI: http://dx.doi.org/10.33448/rsd-v9i11.10511

Figura 3 - Ambientes componentes do jogo.

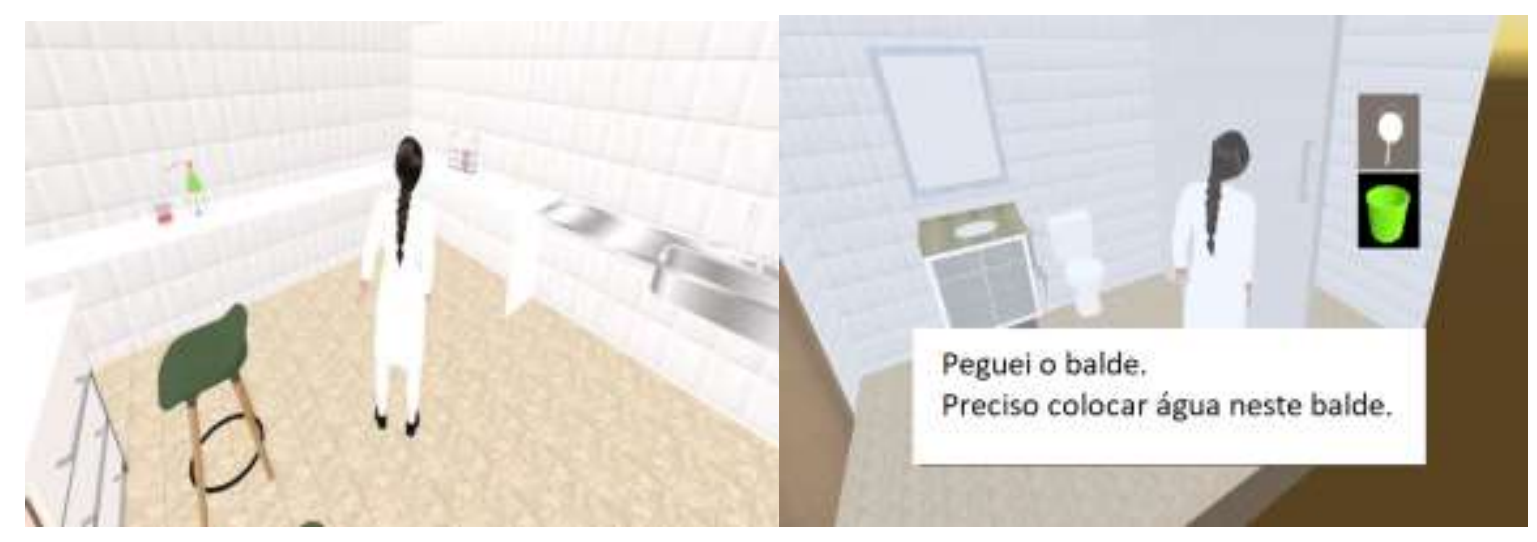

a) Laboratório

b) Banheiro

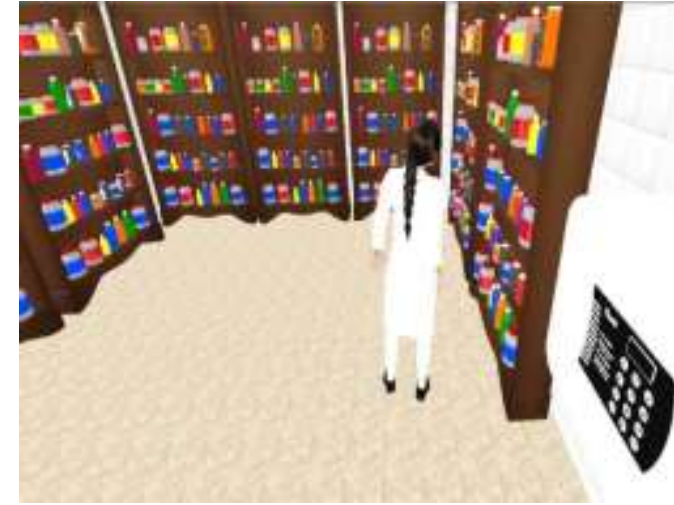

c) Almoxarifado

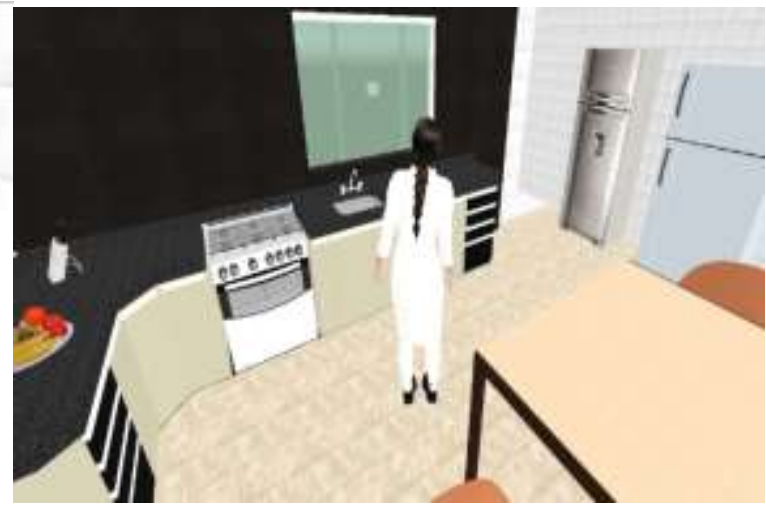

d) Cozinha

Fonte: Autores (2020).

Nestes ambientes vários objetos permitem interação e, como pode ser visto na Figura 3b, objetos coletados são mostrados no inventário localizado nos espaços laterais da tela. A lista onde são adicionados estes objetos é chamada bag, e ela permite que a personagem carregue consigo os objetos como no exemplo, onde a personagem pega um balde e um espelho de mão. Estes objetos são utilizados para solucionar quebra-cabeças e situaçõesproblema que envolvem o conhecimento de química.

No ambiente Laboratório encontra-se um caderno de anotações (Figura 4) contendo textos explicativos sobre química que podem ser consultados a qualquer momento pelo jogador. 
Research, Society and Development, v. 9, n. 11, e98691110511, 2020

(CC BY 4.0) | ISSN 2525-3409 | DOI: http://dx.doi.org/10.33448/rsd-v9i11.10511

Figura 4 - Caderno de anotações disponível para consulta do jogador.

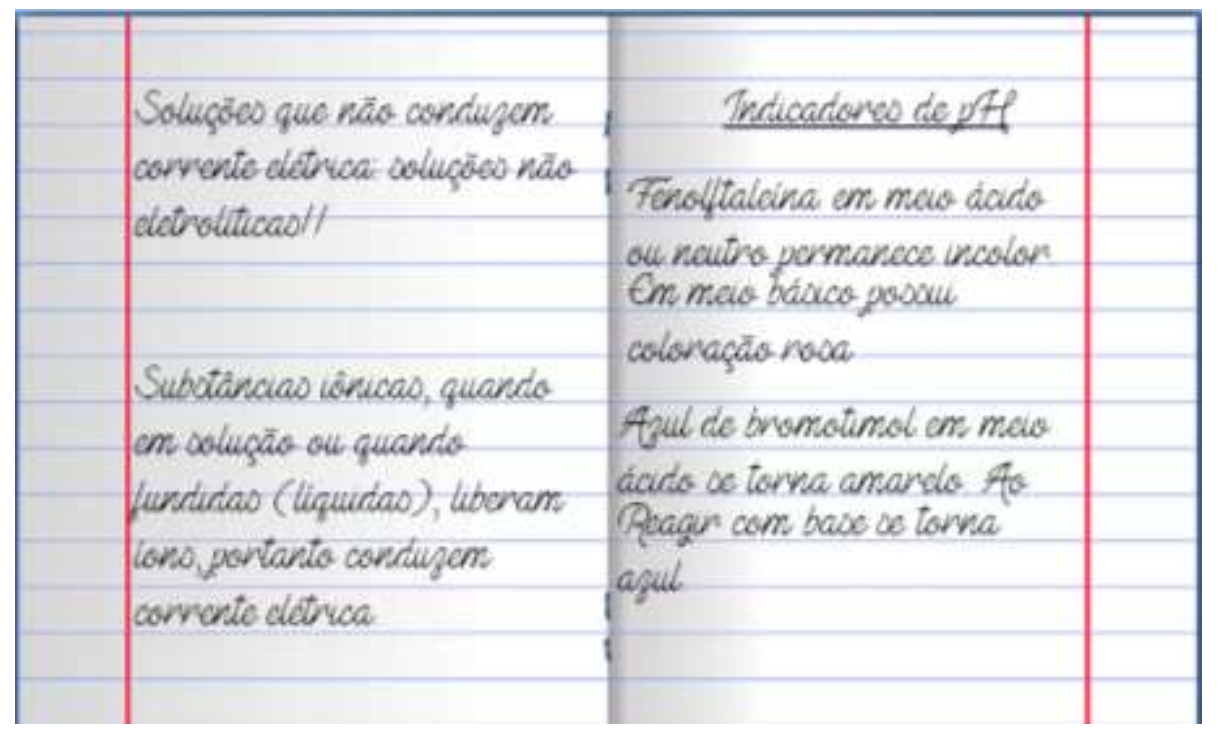

Fonte: Autores (2020).

O caderno de anotações consiste em uma compilação dos conteúdos de química contemplados nos quebra-cabeças e situações problemas que compõem o jogo e auxiliam o usuário na resolução dos enigmas propostos. Alguns enigmas envolvem situações estritamente teóricas, como é o caso do quebra-cabeça Funções Inorgânicas (Figura 5) e o quebra-cabeça dos Cartões (Figura 6).

Figura 5 - Quebra-cabeça Funções Inorgânicas.

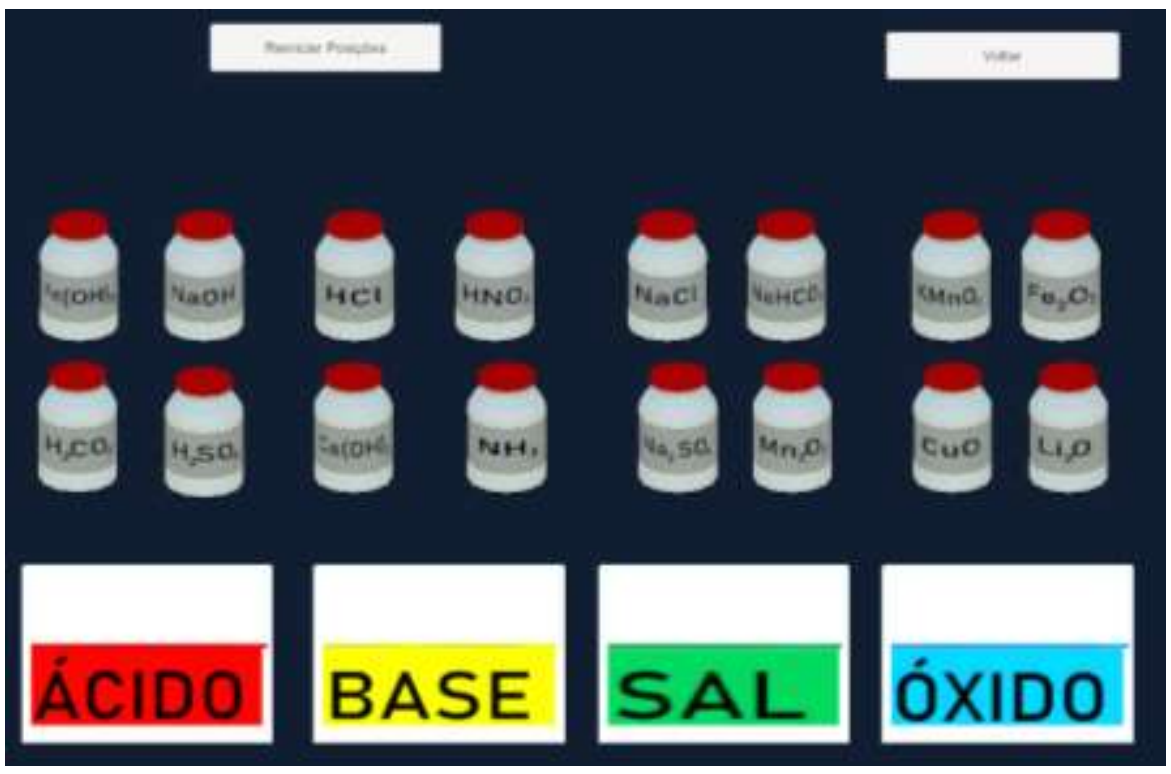

Fonte: Autores (2020). 
O quebra-cabeça Funções Inorgânicas utiliza a classe DragTransform para permitir que os cubos sejam arrastados. Neste jogo o objetivo é colocar as substâncias químicas nas caixas corretas de acordo com sua classificação inorgânica. Uma classe de verificação de resultados é executada sempre que um cubo é adicionado a uma caixa. Somente quando todos os cubos estão na caixa correta o jogo é completado.

O quebra-cabeça dos Cartões (Figura 6) também utiliza a classe DragTransform para permitir que os as cartas sejam arrastadas.

Figura 6 - Quebra-cabeça dos Cartões.

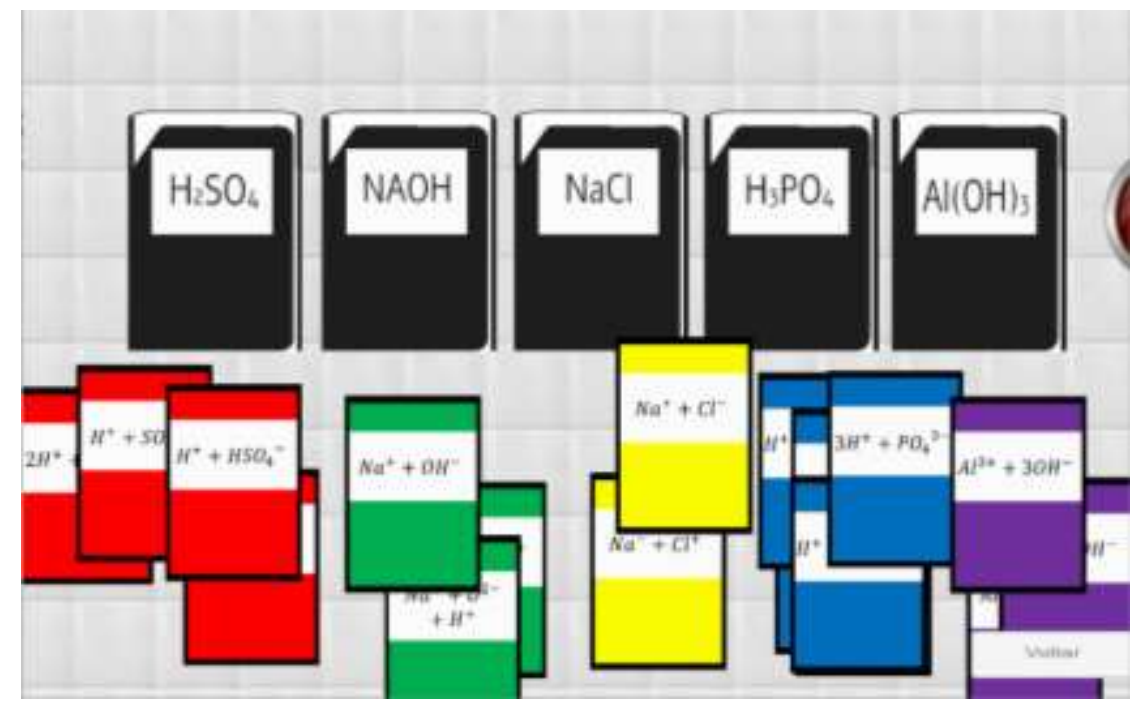

Fonte: Autores (2020).

Este enigma tem por objetivo a associação correta entre a substância em questão e seus possíveis produtos de dissociação iônica (ou ionização, se for o caso). É o único quebracabeça presente no jogo EscapeLab no qual os itens passíveis de interação não serão utilizados em sua totalidade. Alguns cartões apresentam produtos de dissociação iônica/ionização incorretos de forma que o jogador precisa estar atento às cargas das substâncias, atomicidade e coeficiente estequiométrico.

O quebra-cabeça Indicador Ácido-Base (Figura 7) envolve uma situação prática na qual o jogador simula um experimento para encontrar uma senha. 
(CC BY 4.0) | ISSN 2525-3409 | DOI: http://dx.doi.org/10.33448/rsd-v9i11.10511

Figura 7 - Quebra-cabeça Indicador Ácido-Base.

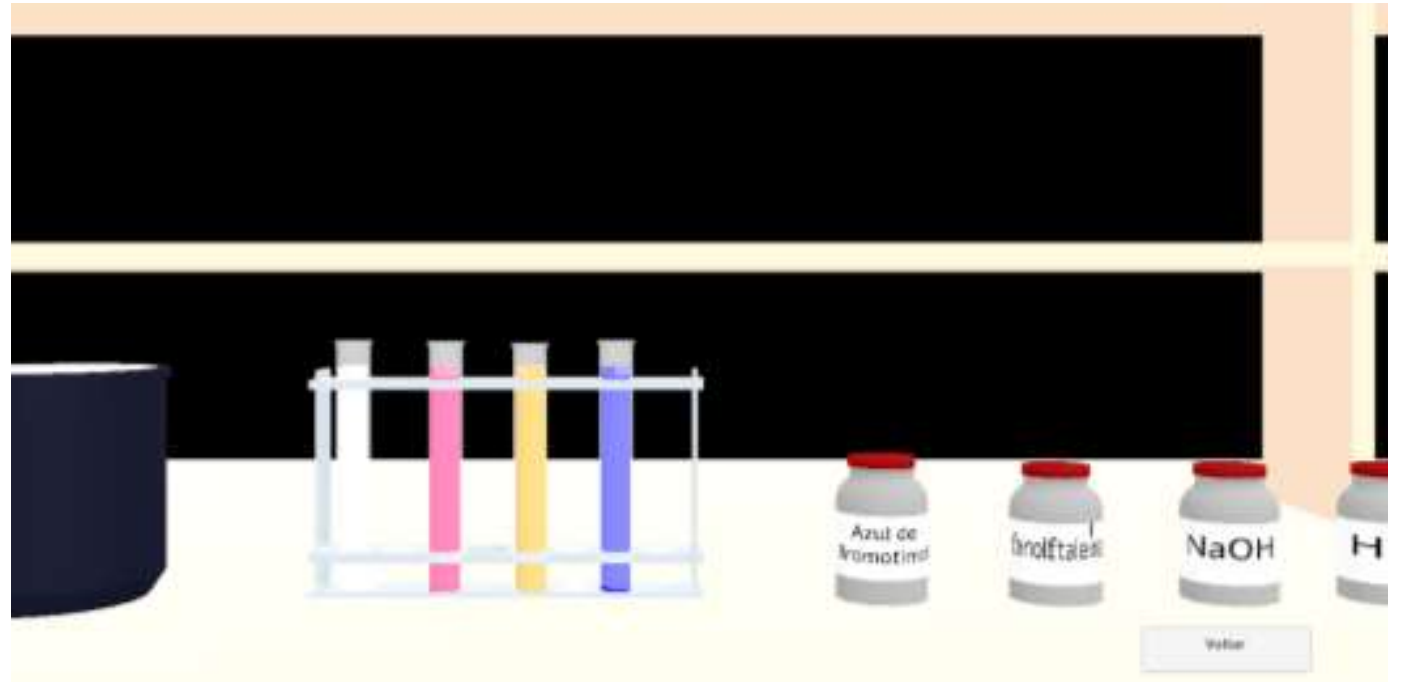

Fonte: Autores (2020).

O quebra-cabeça Indicador Ácido-Base conta com a classe DragTransform que permite arrastar objetos, enquanto a classe Tubes tem funcionalidades tais como detecção de inicio de colisão ou fim de colisão com outros objetos herdadas da classe Collider pertencente a API da Unity Engine. A classe Tubes também é responsável pela mudança de cores do interior dos tubos de ensaio permitindo que o experimento seja simulado por meio da mistura das substâncias químicas. O objetivo final deste enigma é obter uma combinação de cores específica, a partir de soluções ácida e básica em presença de indicadores de pH (azul de bromotimol e fenolftaleína), para que uma senha possa ser revelada.

Outras três situações que envolvem simulação de experimentos podem ser observadas nas Figuras 8, 9 e 10. 
(CC BY 4.0) | ISSN 2525-3409 | DOI: http://dx.doi.org/10.33448/rsd-v9i11.10511

Figura 8 - Situação problema envolvendo transição de fases.

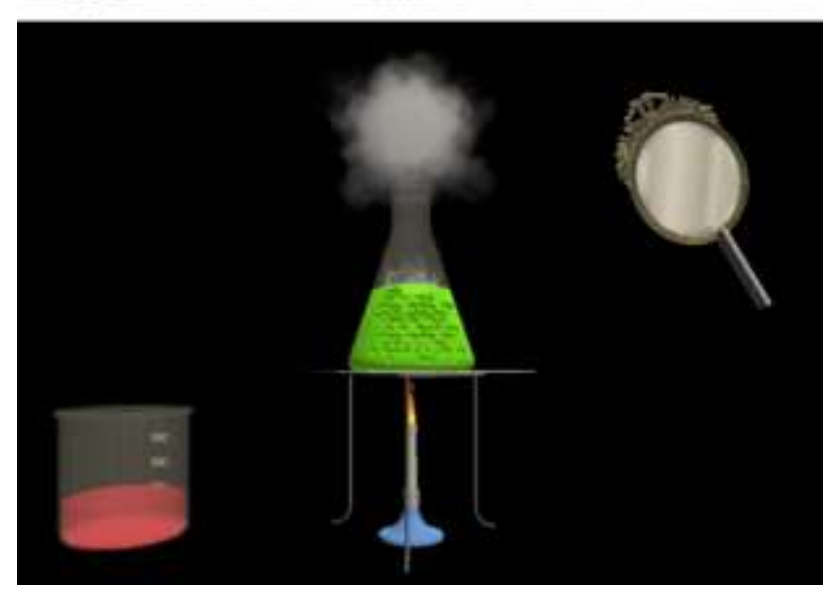

(a)

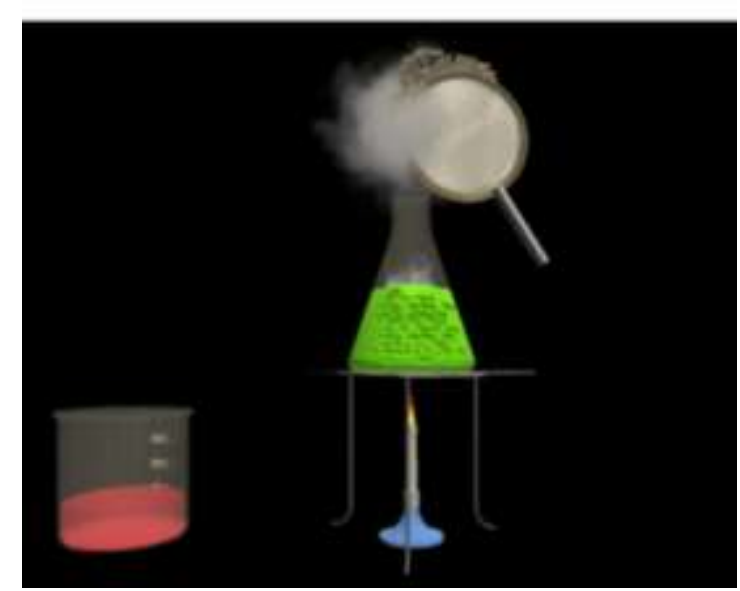

(b)

Fonte: Autores (2020).

Na situação problema ilustrada na Figura 8, o usuário tem por objetivo encontrar uma palavra oculta no espelho (Figura 8a) que será utilizada como senha do computador presente no ambiente Escritório. Para realizar esta ação, é necessário aquecer um líquido de forma a produzir vapor e, ao embaçar o espelho, a palavra é revelada (Figura 8b). 
Research, Society and Development, v. 9, n. 11, e98691110511, 2020

(CC BY 4.0) | ISSN 2525-3409 | DOI: http://dx.doi.org/10.33448/rsd-v9i11.10511

Figura 9 - Situação problema envolvendo reação entre ácido sulfúrico e metal seguida de combustão.
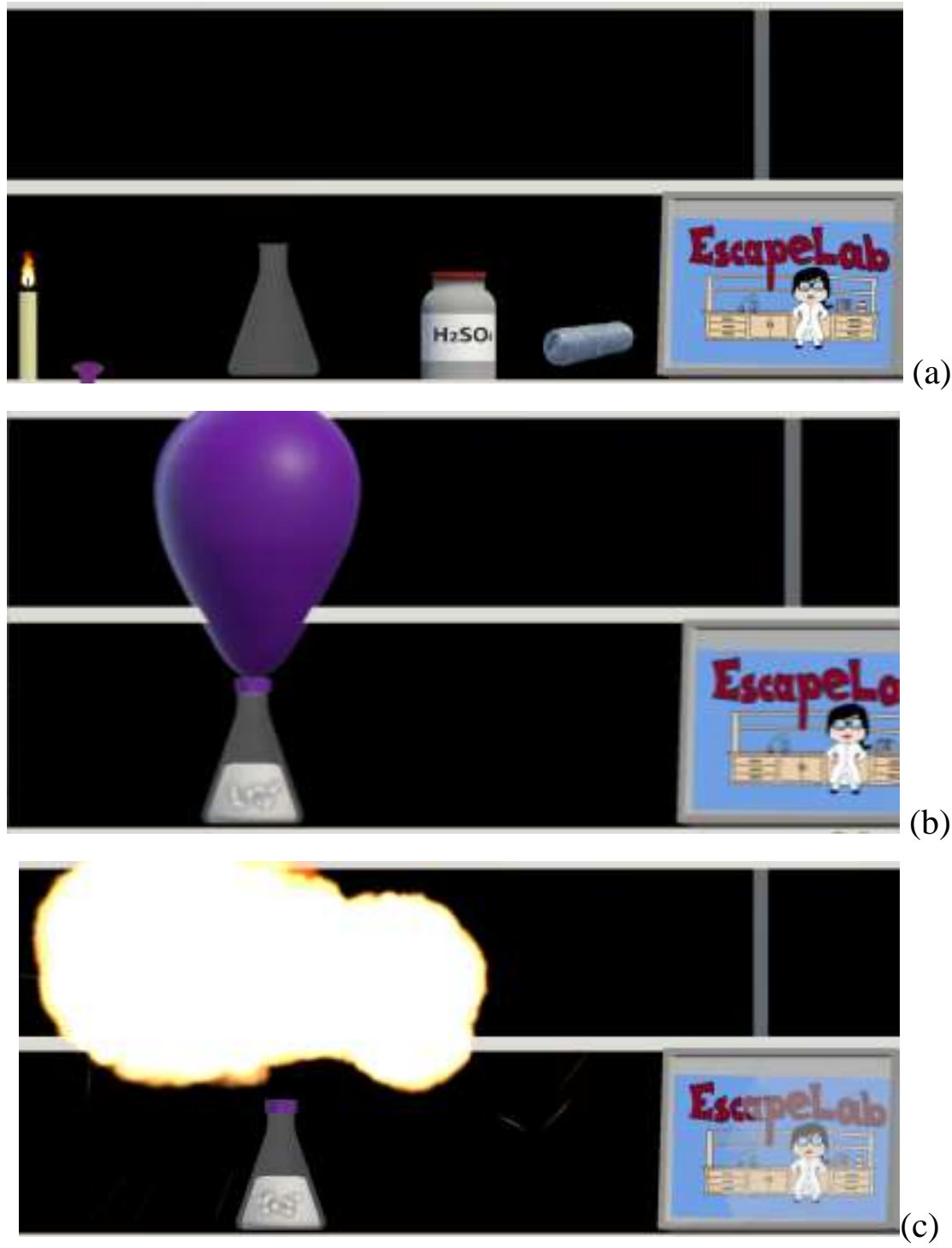

Fonte: Autores (2020).

Na situação problema apresentada na Figura 9 o jogador deve realizar a reação entre ácido sulfúrico e metal (lã de aço) (Figura 9a) para produzir gás hidrogênio que será coletado no balão de borracha (Figura 9b). Posteriormente, a vela é aproximada ao balão ocasionando a combustão do gás produzido (Figura 9c). Como consequência, o quadro localizado no canto inferior direito é danificado e revela um dos cartões necessários para preencher as lacunas da tabela periódica localizada na porta de saída. A vela utilizada para produzir a combustão foi previamente acesa, em outro ambiente, com auxílio de uma reação exotérmica entre glicerina e permanganato de potássio. 
(CC BY 4.0) | ISSN 2525-3409 | DOI: http://dx.doi.org/10.33448/rsd-v9i11.10511

Figura 10 - Simulação do teste de chama.

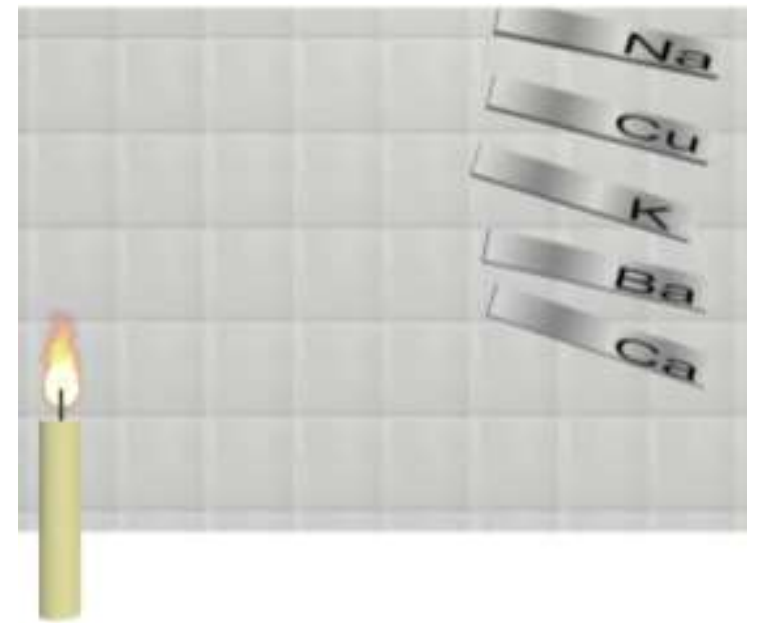

(a)

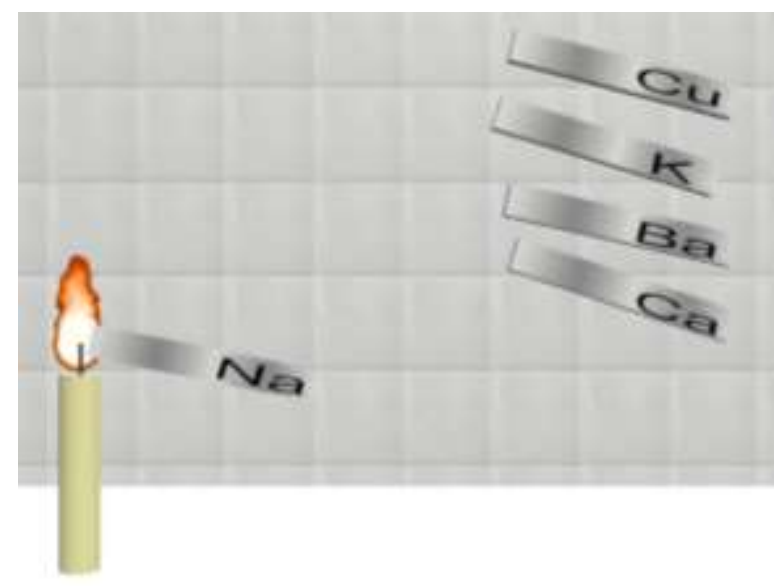

(c)

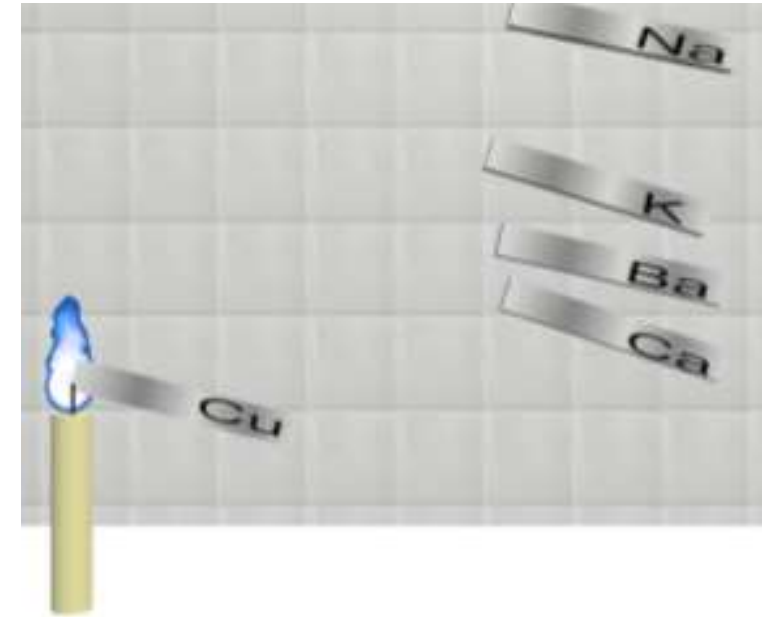

(b)

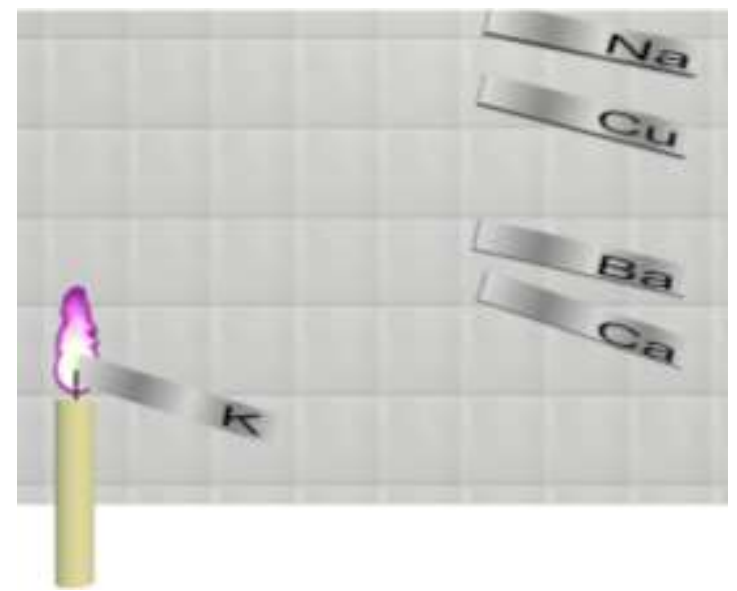

(d)

Fonte: Autores (2020).

O teste de chama faz parte da solução de uma situação problema que envolve a abertura de um cadeado cuja senha é uma sequência de cores. São analisadas as cores das chamas de cinco elementos: sódio $(\mathrm{Na})$, cobre $(\mathrm{Cu})$, potássio $(\mathrm{K})$, bário $(\mathrm{Ba})$ e cálcio $(\mathrm{Ca})$. A chama, na sua coloração natural (Figura 10a), sofre alteração de cor quando em contato com as substâncias mencionadas acima, apresentando a coloração característica de cada elemento em questão (Figuras 10b, 10c e 10d).

Assim que todos os quebra-cabeças e soluções problemas são solucionados o jogador terá acesso aos três cartões necessários para completar a tabela periódica da porta de saída, finalizando o jogo. 


\subsection{Aplicação do jogo EscapeLab}

Os alunos realizaram a atividade com êxito sendo que o tempo médio para finalizar o jogo foi 60 minutos. Ressalta-se que houve pouca interferência da professora na realização da atividade no que diz respeito a intervenções relacionadas ao conteúdo de química, contribuindo para o desenvolvimento da autonomia do aluno no processo de aprendizagem.

Entretanto, no quebra-cabeça dos Cartões, os alunos apresentaram maior dificuldade sendo necessária a cooperação da professora. De acordo com Galafassi et al. (2013) um dos aspectos pedagógicos de suma importância no uso de objetos virtuais de aprendizagem é a cooperação, uma vez que permite trocas de informação durante o processo de aprendizagem. O Quebra-cabeça dos cartões contempla os conteúdos dissociação iônica e ionização, e a maior dificuldade dos alunos foi prever os possíveis produtos gerados na dissociação/ionização das substâncias apresentadas, mais especificamente: carga iônica, atomicidade e coeficientes estequiométricos das espécies químicas. A professora utilizou a espécie química mais complexa do referido quebra-cabeça (ácido fosfórico) para explicar o processo de ionização do referido ácido. Após a explanação os alunos foram capazes de prever os produtos de dissociação/ionização das demais substâncias presentes no quebracabeça.

Ao analisar os resultados do pré-teste e pós-teste foi possível verificar o ganho de conhecimento obtido em cada questão. O resultado das 6 questões de múltipla escolha está apresentado na Figura 11.

Figura 11 - Resultado da Análise Quantitativa.

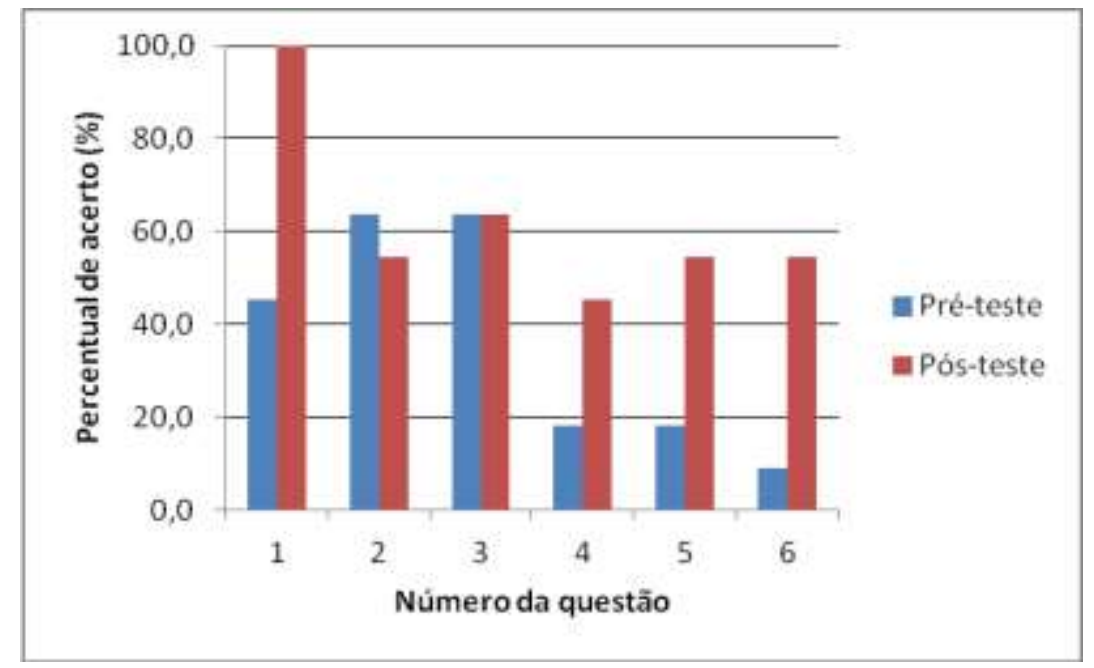

Fonte: Autores (2020). 
Foi possível constatar aumento de acertos em 5 questões após a aplicação do jogo, variando de $27 \%$ a 54,5\%. Na questão 3 não houve alteração no resultado do pré e pós teste enquanto na questão 2 houve um decréscimo de 9,1\% de acertos. Para as questões de relacionar colunas, constatou-se um aumento de acerto de $14 \%$ e $29 \%$ no pós-teste. Por meio destes resultados podemos constatar quais áreas de conhecimento tiveram maior efetividade e quais devem ser reconsideradas quanto ao método de abordagem.

A questão 2 foi a única que apresentou um decréscimo de acertos após a aplicação do jogo. O conteúdo desta questão foi abordado no quebra-cabeça Indicador Ácido-Base. Neste enigma o objetivo era realizar uma sequência de quatro cores, utilizando apenas 2 substâncias químicas (um ácido e uma base) e 2 indicadores de pH. Em função das poucas opções de combinações possíveis é passível a solução do quebra-cabeça por meio de tentativas. Desta forma o aspecto pedagógico cognição, definido por Galafassi et al. (2013) como a capacidade do objeto virtual de aprendizagem transmitir um conhecimento real e significativo ao aprendiz, não foi contemplado de forma eficaz. É necessária, portanto, uma reformulação do quebra-cabeça Indicador Ácido-Base de forma a dificultar a sua resolução por tentativas para que o mesmo transmita o conhecimento da forma desejada.

Vale destacar que os alunos apresentaram melhor rendimento nas questões cujos conteúdos estavam relacionados às situações problema, as quais foram abordadas por meio de simulações de experimentos, quando comparado aos resultados obtidos nas questões relacionadas aos conteúdos químicos dos quebra-cabeças que não simularam experimentos. Diversos autores (Santos \& Nagashima, 2017; Silva Júnior \& Parreira, 2016; Oliveira, 2010; Galiazzi \& Gonçalves, 2004) relatam os benefícios do uso de experimentos no ensino de química como agente facilitador e motivador do processo de ensino-aprendizagem. Portanto, pode-se afirmar que o uso de experimentos, mesmo que de forma simulada, contribuem na obtenção da informação.

A análise qualitativa teve por objetivo investigar a aceitação e percepção dos alunos em relação ao jogo EscapeLab como ferramenta de aprendizagem. Os resultados da análise qualitativa estão apresentados na Figura 12. 
Figura 12 - Resultado da Análise Qualitativa.

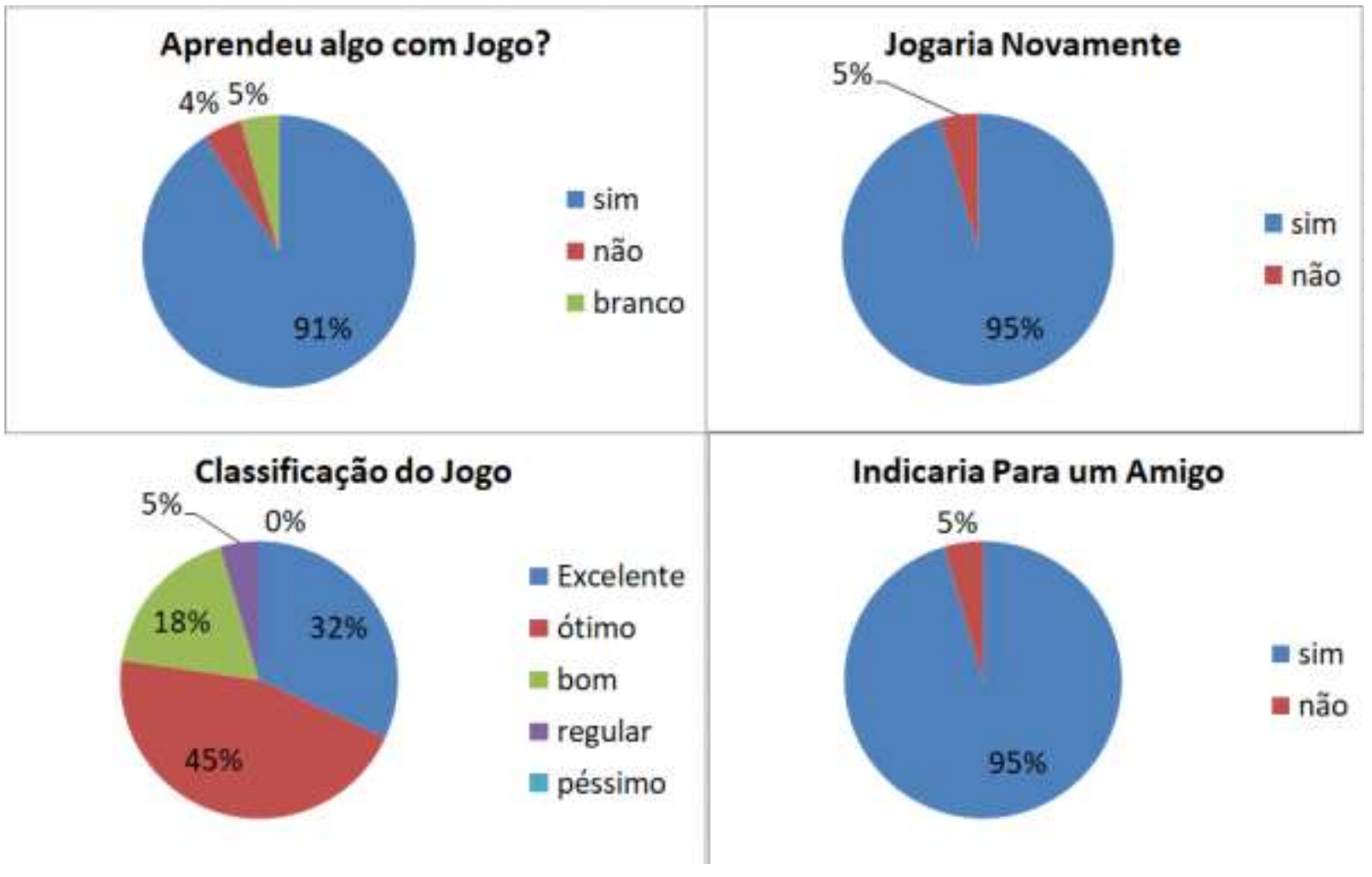

Fonte: Autores (2020).

Como pode ser observado $91 \%$ dos alunos consideraram que houve aprendizado com o jogo evidenciando, juntamente com a análise quantitativa, a eficácia do uso de atividades lúdicas como agente facilitador do processo de aprendizagem, uma vez que o jogo EscapeLab foi capaz de transmitir conhecimento significativo melhorando a compreensão conceitual do usuário. O jogo foi considerado ótimo ou excelente por $77 \%$ dos usuários e $95 \%$ afirmaram que jogariam novamente e indicariam para amigos. Desta forma, pode-se inferir que o objeto virtual de aprendizagem atingiu seu objetivo uma vez que teve resultado positivo no conhecimento adquirido bem como foi bem aceito pelo público alvo.

\section{Considerações Finais}

Um objeto virtual de aprendizagem foi elaborado e implementado na forma de um jogo educativo, utilizando ferramentas gratuitas que permitiram um orçamento de baixo custo e, desta maneira, os objetivos foram alcançados.

Através da aplicação do software desenvolvido pode-se observar que um jogo educativo devidamente selecionado e monitorado por um professor apto, se mostra uma forma de ensino e aprendizagem eficiente. 
A principal contribuição do presente trabalho para a sociedade está relacionada à possível inclusão digital e despertar do gosto pela ciência nos jovens, uma vez que o jogo permite que eles estudem e se divirtam de maneira simultânea. Para trabalhos futuros outras formas de aplicações e outras disciplinas poderão ser abordadas para que se obtenha resultados equivalentes ou melhores.

\section{Agradecimentos}

Os autores agradecem ao Instituto Federal de Minas Gerais - campus Bambuí e ao Programa Integração do Instituto Federal de Educação, Ciência e Tecnologia de Minas Gerais campus Bambuí pela possibilidade de desenvolvimento do projeto e fornecimento dos subsídios necessários ao desenvolvimento deste trabalho.

\section{Referências}

Cleophas, M. G. \& Cavalcanti, E. L. D. (2020). Escape Room no Ensino de Química. Química Nova na Escola, 42(1), 45-55.

Focetola, P. B., Castro, P. J., Souza, A. C. J., Grion, L. S., Pedro, N. C. S., Iack, R. S., Almeida, R. X., Oliveira, A. C., Barros, C. V. T., Vaitsman, E., Brandão, J. B., Guerra, A. C. O. \& Silva, J. F. M. (2012). Os jogos educacionais de cartas como estratégia de ensino em química. Química nova na escola, 34(4), 248-255.

Galafassi, F. P., Gluz, J. C. \& Galafassi, C. (2013). Análise crítica das pesquisas recentes sobre as tecnologias de objetos de aprendizagem e ambientes virtuais de aprendizagem Revista Brasileira de Informática na Educação, 21(3), 41-52.

Galiazzi, M. C. \& Gonçalves, F. P. (2004). A natureza pedagógica da experimentação: uma pesquisa na Licenciatura em Química. Química Nova, 27(2), 326-331.

Gonçalves, L., Giacomazzo, G., Rodrigues, F., \& Macaia, B. (2016). Gamificação na Educação: um modelo conceitual de apoio ao planejamento em uma proposta pedagógica. In Simpósio Brasileiro de Informática na Educação-SBIE, 27(1), 1305. 
Gregório, J. R., Leite, C. C., Leal, B. C., Nitschke, W. K., Pederzolli, F. R. S., Nobre, K. M., Fraga, M. V. B \& Silva, C. B. (2017) O Programa de Apoio à Graduação em Química (PAGQuímica) e sua contribuição para a democratização e permanência dos estudantes no ensino superior. Revista Electrónica de Enseñanza de las Ciencias, 16(3), 540-558.

Kapp, K. M. (2012). The gamification of learning and instruction: game-based methods and strategies for training and education. John Wiley \& Sons.

Nunes, A. S. \& Adorni, D.S. (2010) O ensino de química nas escolas da rede pública de ensino fundamental e médio do município de Itapetinga-BA: O olhar dos alunos. Encontro Dialógico Transdisciplinar - Enditrans, Vitória da Conquista, Bahia, Brasil.

Oliveira, J. R. S. (2010) Contribuições e abordagens das atividades experimentais no ensino de ciências: reunindo elementos para a prática docente. Acta Scientiae, 12(1), 139- 153.

Resende, E. C., Sales, P. F., Soares, V. C., Teixeira, M. C. \& Duarte, C. J. (2020). Jogos educativos como agente facilitador no processo de aprendizagem de Química. ForScience, $8(2), 1-16$.

Ryan, R. M., \& Deci, E. L. (2017). Self-determination theory: Basic psychological needs in motivation, development, and wellness. Guilford Publications.

Santos, D. M. \& Nagashima, L. A. (2017). Potencialidades das atividades experimentais no ensino de química potencial of experimental activities in chemistry education. REnCiMa, 8(3), 94-108.

Silva Júnior, E. A. \& Parreira, G. G. (2016). Reflexões sobre a importância da experimentação no ensino da Química no ensino médio. Revista Tecnia, 1(1), 67-82.

Soares, M. H. F. B. (2016). Jogos e atividades lúdicas no ensino de química: uma discussão teórica necessária para novos avanços. REDEQUIM, 2(2), 5-13.

Spinelli, W. (2005). Aprendizagem matemática em contextos significativos: objetos virtuais de aprendizagem e percursos temáticos. Universidade de São Paulo, São Paulo, 2005. 
Research, Society and Development, v. 9, n. 11, e98691110511, 2020

(CC BY 4.0) | ISSN 2525-3409 | DOI: http://dx.doi.org/10.33448/rsd-v9i11.10511

\section{Porcentagem de contribuição de cada autor no manuscrito}

Diogo Xavier de Noronha - 34\%

Gabriel da Silva - $33 \%$

Vássia Carvalho Soares - 33\% 